\title{
Ecological and functional technical mortars with rubber
}

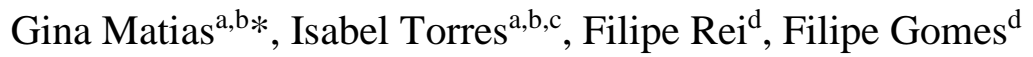 \\ ${ }^{a}$ ITeCons - Inst. Research Tech. Dev. Construction, Energy, Environment and Sustainability, 3030-289 Coimbra, Portugal \\ ${ }^{b}$ ADAI/LAETA, Association for the Development of Industrial Aerodynamics, University of Coimbra, 3030-289 Coimbra, Portugal \\ ${ }^{c}$ Department of Civil Engineering, Faculty of Sciences and Technology, University of Coimbra, 3030-788 Coimbra, Portugal \\ ${ }^{d}$ Primefix - Colas e Argamassas Técnicas, Lda., 3780-244 Aguim, Anadia, Portugal
}

\begin{abstract}
The finishing coatings of buildings, such as plasters and renders, are essential for the durability and sustainability of constructive solutions. Mortars provide constructive elements with protection and contribute significantly to thermal and acoustic comfort of the indoor environment. The development of ecological mortars with specific characteristics in response to the need for more sustainable construction represents an important challenge.

Considering the current quality requirements for mortar industries regarding technical specificities and the environment, it is fundamental that more recycled or natural raw materials, and material with lower environmental impact are introduced. Furthermore, the development of multifunctional mortars suited for different substrates ensures more versatility of the products. Looking to address these issues, this paper presents the development of mortars incorporating granulated rubber from used tires. This residue has been considered for the development of construction materials due to its lightness, elasticity and energy absorption capacity. It also provides improved thermal and acoustic behaviour.

For this purpose, 2 different mortar compositions with fine rubber granulate were analysed. Mechanical behaviour for different substrates was determined through compressive and flexural strength, dynamic elasticity modulus and adhesive strength. The hygrothermal behaviour of the mortars was also evaluated considering the results obtained for water vapour permeability, capillary absorption and thermal conductivity tests.

Very promising results were obtained in this study. These allow the framing of these mortars in the recent context of CE marking requirements for rendering and plastering mortars.
\end{abstract}

(C) 2018 The Authors. Published by Diamond Congress Ltd., Budapest University of Technology and Economics Peer-review under responsibility of the scientific committee of the Creative Construction Conference 2018.

Keywords: Mortars; Multifunctionality; Recycling; Rubber Residues; Sustainability.

\section{Introduction}

The most recent environmental requirements have led to the research and development of ecological mortars incorporating by-products from several different industries. The processing of raw materials by industries generates tons of residues which are, most of the times, incinerated or deposited into landfills. These processes represent a considerable ecological footprint which can be reduced by the introduction of these residues in other production activities. In the construction market, several cementitious based materials such as bricks, concrete and mortars incorporating residues from glass, ceramics [1,2], cork [3-5], rubber, polymeric materials, among others [6] have emerged. In addition to ecological advantages, these by-products may also improve the hygrothermal [7-9], acoustic [10] and mechanical behaviour of concretes and mortars. The development of ecological and functional technical mortars for new constructions, or for rehabilitation purposes, requires the assessment of the feasibility of the incorporation of by-products, considering their regional and national availability. 
The use of recycled rubber from tires may be done through 3 different ways: reutilization, recycling or energy recovery. Any of these allow the reduction of the environmental impact related to the extension life-cycle of this product. The incorporation of rubber residues in mortars might be included in the first or second ways that is reutilization or recycling.

There are several studies dedicated to the development of mortars with rubber from tires. The use of this material as a partial replacement of natural aggregates is very well documented and it is supported by experimental research [11-16]. This residue has become more accepted in construction due to its intrinsic characteristics, such as lightness (lower density), higher elasticity and higher energy absorption. Besides, it provides improved thermal and acoustic behaviour. The percentage of rubber and particles sizes have major influence on the properties of mortars, in fresh or hardened state. A synthesis of the influence that incorporating rubber has on several relevant properties is presented in Table 1.

Table 1: Effect of replacing of natural aggregate with rubber.

\begin{tabular}{ll}
\hline \multicolumn{1}{c}{ Property } & \multicolumn{1}{c}{ Effect of replacing natural aggregate with rubber } \\
\hline Water absorption & $\begin{array}{l}\text { Non-consensual data } \\
\text { Decreases with the increase of the \% of rubber } \\
\text { Bulk density }\end{array}$ \\
$\begin{array}{l}\text { Decreases with the increase of the \% of rubber } \\
\text { Decreases with the growth of the particles size } \\
\text { Decreases with the increase of the \% of rubber (the influence of particles } \\
\text { size is not clear) }\end{array}$ \\
$\begin{array}{ll}\text { Increases with the increase of the \% of rubber } \\
\text { Voids percentage }\end{array}$ \\
$\begin{array}{l}\text { Decreases with the increase of the \% of rubber (the influence of particles } \\
\text { size is negligible) }\end{array}$ \\
Increases with the increase of the \% of rubber
\end{tabular}

Aggregates from rubber tires might be obtained in two ways: mechanical crushing or cryogenic crushing. In the mechanical process, rubber is fragmented using several crushers and mills. Steel is separated magnetically and the textiles are separated from density differences. After that, rubber granules are separated in different ranges, according to the size of the particles, by sieving with mesh. In the cryogenic process, liquid nitrogen is used to freeze the rubber, which allows its fragmentation and, consequently, the production of fine rubber aggregate. Initially, the rubber is crushed and then transported to a cryogenic tunnel where the nitrogen input temperature is approximately ($192)^{\circ} \mathrm{C}$, and the output temperature is about $(-80)^{\circ} \mathrm{C}$. After crossing the cryogenic tunnel and the pneumatic hammers, the steel and textiles from the tires are separated from the rubber by a magnetic apparatus and with suction, respectively.

Some of the most interesting properties of rubber aggregates are:

- Non-floatable or with reduced floatability;

- Stability over time;

- Very good elastic response per unit mass;

- Meets the PAH's test (polycyclic aromatic carbonates harmlessness / toxicology);

- Safe for health according to OSHA OMB N. ${ }^{\circ} 1218-0072$;

- Meets the DIN V 18035-7 related to the emission of leaching of heavy metals and organic pollutants;

- Does not release carbon black (does not dirty the skin or clothes);

- Compaction, friction and abrasion resistant;

- Almost non smelling;

- Resistant to UV radiation;

- Resistant to weather.

The present study was framed within the "EFTM - Functional Technical Mortars" founded project, which focused on developing an ecological and multifunctional mortar incorporating rubber residues with ability to be applied onto different substrates. Two different compositions were analysed and compared in what concerns to their workability, flexural and compressive strength, dynamic elasticity modulus, adhesive strength, water vapour permeability, water absorption by capillary action, bulk density and thermal conductivity. The results were also compared to the requirements established by the specification for mortar for rendering and plastering, EN 998-1. 


\section{Experimental program}

\subsection{Mortar characterization}

After some preliminary laboratory tests with different proportions, two different mortars with rubber granulates were selected and characterized. The two selected mixtures were the ones which presented, after an empiric analysis based on visual inspection, workability and earliest shrinkage.

The rubber dust used in the mixtures was obtained by cryogenic processes, which allowed the maintenance of its most interesting characteristics. The cryogenic cooling of the polymers from rubber, by means of liquid nitrogen followed by grinding with a high impact hammer mill (without friction, shear strain or abrasion on the rubber surface), provides grains with cubicoid morphology, plain surfaces and with almost no pores. This process does not chemically or thermally degrade the molecular chains of the rubber polymers, nor its vulcanization condition. Its elastic properties (impact absorption; elastic recovery) do not change over time. The durability additions of the tire rubber (antioxidants, UV protection, stabilizers and others) maintain over time, providing high resistance to environmental ageing.

The size of the particles of the rubber dust, exhibited in Figure 1, varies between $0,18 \mathrm{~mm}$ and $0,6 \mathrm{~mm}$. The particles present a density of $0,454 \mathrm{~g} / \mathrm{cm}^{3}$.

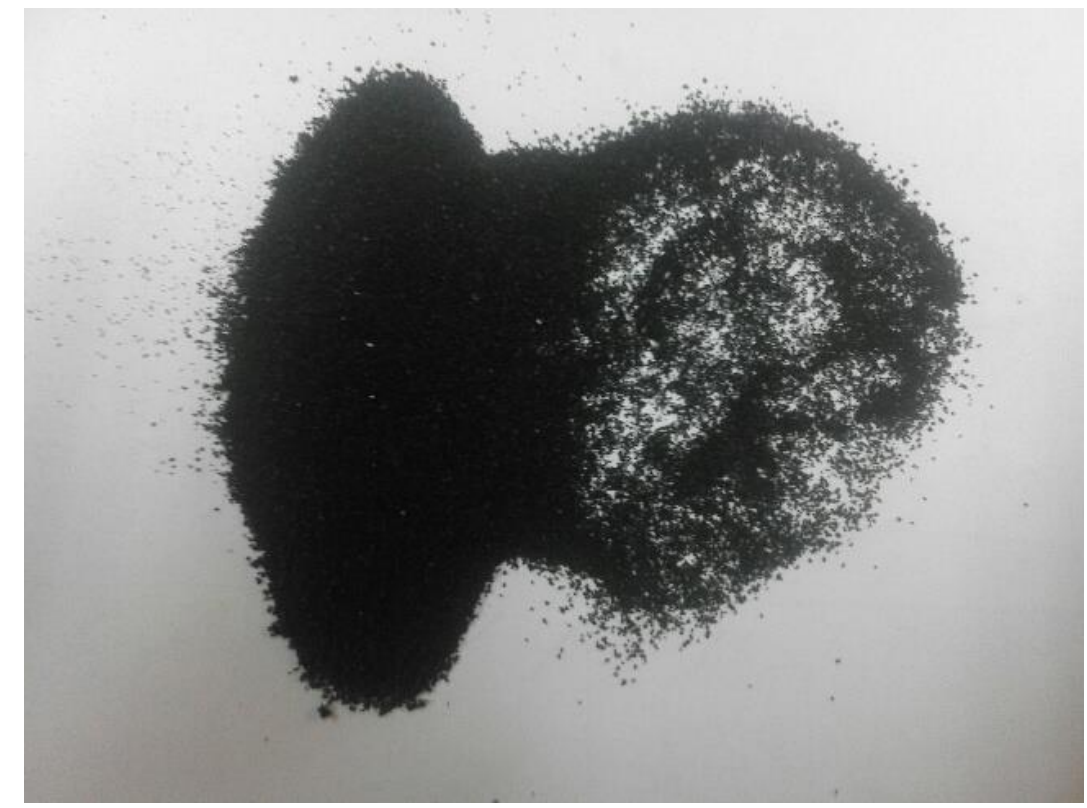

Fig. 1. Rubber dust

Rubber dust mortars were produced with about 30\%, in mass, of binder (Portland cement), $12 \%$ of calcium carbonate, and sand and rubber dust as aggregates. Several additions were also used (water repellents, stabilizers, stiffeners, air introducers, and others), representing $2,8 \%$ of the mixture, in mass.

Table 2 presents all of the characterization tests performed and the respective standards.

The two mortars were designated as Primerubber R20 and Primerubber R35. The amount of water used was determined considering an adequate workability: for Primerubber R20, $220 \mathrm{ml} / \mathrm{kg}$ dry mixture was used, and for Primerubber R35, $270 \mathrm{ml} / \mathrm{kg}$ dry mixture was used. Primerubber R20 presented a Flow value of $164 \mathrm{~mm}$, and Primerubber R35 of $166 \mathrm{~mm}$. 
Table 2: Properties determined for the mortars with rubber.

\begin{tabular}{|c|c|}
\hline Properties & Standard procedures \\
\hline \multicolumn{2}{|r|}{ Fresh mortar } \\
\hline Workability (mm) & $\begin{array}{l}\text { Determination of consistence of fresh mortar (by flow table) (EN } \\
\text { 1015-3:1999; EN 1015-3:1999/A1:2004; EN 1015-3:1999/A2:2006) }\end{array}$ \\
\hline \multicolumn{2}{|c|}{ Hardened mortar - mechanical characterization } \\
\hline $\begin{array}{l}\text { Flexural strength - } \mathrm{R}_{\mathrm{F}}\left(\mathrm{N} / \mathrm{mm}^{2}\right) \\
\text { Compressive strength }-\mathrm{R}_{\mathrm{C}}\left(\mathrm{N} / \mathrm{mm}^{2}\right)\end{array}$ & $\begin{array}{l}\text { Determination of flexural and compressive strength of hardened } \\
\text { mortar (EN 1015-11:1999; EN 1015-11:1999/A1:2006) }\end{array}$ \\
\hline Dynamic Modulus of Elasticity - EdL (MPa) & $\begin{array}{l}\text { Determination of the dynamic modulus of elasticity (by measuring the } \\
\text { fundamental resonance frequency) (based on NP EN 14146:2006 - } \\
\text { Method 5.2, for natural stone) }\end{array}$ \\
\hline Adhesive strength $-\mathrm{f}_{\mathrm{u}}\left(\mathrm{N} / \mathrm{mm}^{2}\right)$ & $\begin{array}{l}\text { Determination of adhesive strength of hardened rendering and } \\
\text { plastering mortars on substrates (EN 1015-12:2000) }\end{array}$ \\
\hline \multicolumn{2}{|c|}{ Hardened mortar - physical characterization } \\
\hline Water vapour permeability coefficient - $\mu(-)$ & $\begin{array}{l}\text { Determination of water vapour permeability of hardened rendering } \\
\text { and plastering mortars (NP EN 1015-19:2008) }\end{array}$ \\
\hline Dry bulk density $\left(\mathrm{kg} / \mathrm{m}^{3}\right)$ & $\begin{array}{l}\text { Determination of dry bulk density of hardened mortar (EN 1015- } \\
\text { 10:1999; EN 1015-10:1999/A1:2006) }\end{array}$ \\
\hline Water absorption coefficient $-\mathrm{C}_{\mathrm{m}}\left(\mathrm{kg} /\left(\mathrm{m}^{2} \cdot \mathrm{min}^{0.5}\right)\right)$ & $\begin{array}{l}\text { Determination of water absorption coefficient due to capillary action } \\
\text { of hardened mortar (EN 1015-18:2002) }\end{array}$ \\
\hline Thermal conductivity $10^{\circ} \mathrm{C}\left[\mathrm{W} /\left(\mathrm{m} .{ }^{\circ} \mathrm{C}\right)\right]$ & \multirow{2}{*}{$\begin{array}{l}\text { Determination of thermal resistance by means of guarded hot plate and } \\
\text { heat flow meter methods (EN 12664:2001; ISO 8302:1991) }\end{array}$} \\
\hline Thermal conductivity - EN $1745-\lambda_{23, \text { dry,mat }}[\mathrm{W} /(\mathrm{m} . \mathrm{K})]$ & \\
\hline
\end{tabular}

\subsection{Mechanical characterization}

Table 3 presents the results obtained for the mechanical characterization of the mortars with rubber, including standard deviation and variation coefficient.

Table 3: Test results for mechanical characterization of mortars with rubber.

\begin{tabular}{ccc}
\hline & Primerubber R20 & Primerubber R35 \\
\hline $\mathbf{R}_{\mathbf{F}}\left(\mathbf{N} / \mathbf{m m}^{\mathbf{2}}\right)$ & $\mathbf{2 , 3}$ & $\mathbf{1 , 4}$ \\
$\mathrm{StD}$ & 0,18 & 0,02 \\
C.V. $(\%)$ & 0,08 & 0,02 \\
\hline RC $_{\mathbf{C}}\left(\mathbf{N} / \mathbf{m m}^{\mathbf{2}}\right)$ & $\mathbf{4 , 0}$ & $\mathbf{1 , 7}$ \\
$\mathrm{StD}$ & 0,16 & 0,02 \\
C.V. $(\%)$ & 0,04 & 0,01 \\
\hline EdL $[\mathbf{M P a}]$ & $\mathbf{2 1 7 9}$ & $\mathbf{6 9 2}$ \\
StD & 101,8 & 2,9 \\
C.V. $(\%)$ & 4,7 & 0,4 \\
\hline
\end{tabular}

It was observed that Primerubber R20 presents higher flexural and compressive strength and, consequently, higher elasticity modulus.

Concerning compressive strength, according to EN 998-1 specification standard for rendering and plastering mortars, Primerubber R20 is classified as CS II and Primerubber R35 as CS I or CS II (close to the lower limit of CS II class). 
Since the results obtained for Primerubber R20 were more satisfying, and for logistical reasons, the adhesive strength tests were performed only for this mixture. Adhesive strength tests were performed over different substrates, with or without pre-coating, when necessary. The results are presented in Table 4.

Table 4: Test results for adhesive strength of Primerubber R20 mortar.

\begin{tabular}{|c|c|c|c|c|c|}
\hline Substrate & & $\mathbf{f}_{\mathrm{u}}\left(\mathrm{N} / \mathbf{m m}^{2}\right)$ & StD $\left(\mathbf{N} / \mathbf{m m}^{2}\right)$ & C.V. $(\%)$ & Fracture \\
\hline Perforated ceramic masonry unit & Direct application & 0,19 & 0,04 & 20,7 & Pattern B \\
\hline Perforated concrete masonry unit & Direct application & 0,13 & 0,10 & 74,0 & Pattern B \\
\hline \multirow{2}{*}{ Solid concrete } & Direct application & 0,27 & 0,03 & 9,4 & Pattern B \\
\hline & With primer coat & 0,24 & 0,05 & 22,0 & Pattern B \\
\hline \multirow{2}{*}{ Porcelain stoneware tile } & Direct application & 0,17 & 0,03 & 18,2 & Pattern B \\
\hline & With primer coat & 0,22 & 0,04 & 16,6 & Pattern B \\
\hline \multirow{2}{*}{ Plasterboard } & Direct application & 0,09 & 0,03 & 31,6 & Pattern A \\
\hline & With primer coat & 0,17 & 0,04 & 24,5 & Pattern B \\
\hline \multirow{2}{*}{ Birch plywood } & Direct application & 0,12 & 0,02 & 18,8 & Pattern C \\
\hline & With primer coat & 0,21 & 0,04 & 17,1 & Pattern B \\
\hline \multirow{2}{*}{$\begin{array}{c}\text { MDF Standard } \\
\text { (medium density wood fibreboard) }\end{array}$} & Direct application & 0,09 & 0,02 & 20,6 & Pattern B \\
\hline & With primer coat & 0,09 & 0,02 & 20,6 & Pattern B \\
\hline $\begin{array}{c}\text { Certis }{ }^{\circledR} \\
\text { (cement bonded particleboard) }\end{array}$ & Direct application & 0,18 & 0,05 & 29,7 & Pattern B \\
\hline $\begin{array}{c}\text { OSB3 } \\
\text { (oriented strand board }- \text { wood based) }\end{array}$ & Direct application & 0,03 & 0,01 & 30,7 & Pattern A \\
\hline $\begin{array}{c}\text { ICB } \\
\text { (expanded insulation cork board) }\end{array}$ & Direct application & 0,12 & 0,02 & 15,9 & Pattern C \\
\hline $\begin{array}{l}\text { EPS } \\
\text { (expanded polystyrene insulation board) }\end{array}$ & Direct application & 0,11 & 0,02 & 20,7 & Pattern C \\
\hline
\end{tabular}

In general, it can be said that Primerubber R20 develops good cohesion between several kinds of substrates, including wood-based ones. Lowest values of adhesive strength were obtained for plasterboard without primer, MDF with or without primer and OSB without primer. For those, plasterboard and OSB directly applied onto the substrates presented a fracture pattern type A, adhesion fracture, which means that fracture occurred at the interface between the mortar and substrate. In the specific case of plasterboard, the use of a primer coating solved this issue. For MDF, even with primer, the adhesive strength kept lower, with a type B fracture pattern in both cases, which corresponds to the cohesive fracture occurring in the mortar itself.

Overall, Primerubber R20 presented a type B fracture pattern, except for ICB and EPS supports, in which case the fracture occurred in the substrate material. This behaviour was expected since these substrates have lower mechanical strength.

\subsection{Physical characterization}

Table 5 presents the results obtained for the physical characterization of the mortars with rubber, and includes the standard deviation and variation coefficient. 
Table 5: Test results for physical characterization of rubber mortars.

\begin{tabular}{ccc}
\hline & Primerubber R20 & Primerubber R35 \\
\hline Wvp coefficient, $\boldsymbol{\mu}(-)$ & $\mathbf{1 1 , 1}$ & $\mathbf{7 , 2}$ \\
StD & 0,7 & 0,2 \\
C.V. $(\%)$ & 6,3 & 3,2 \\
\hline Dry bulk density $\left(\mathbf{k g} / \mathbf{m}^{\mathbf{3}}\right)$ & $\mathbf{1 2 0 1}$ & $\mathbf{9 5 5}$ \\
StD & 0,6 & 2,0 \\
C.V. $(\%)$ & 0,1 & 0,2 \\
\hline C $\left(\mathbf{k g} /\left(\mathbf{m}^{2} \cdot \mathbf{m i n}^{\mathbf{0 . 5}}\right)\right)$ & $\mathbf{0 , 2 0}$ & $\mathbf{0 , 1 0}$ \\
StD & 0,00 & 0,00 \\
C.V. $(\%)$ & 0,0 & 0,0 \\
\hline$\lambda_{23, \text { dry,mat }}(\mathbf{W} /(\mathbf{m} . \mathbf{K}))$ & $\mathbf{0 , 2 8 3}$ & $\mathbf{0 , 2 0 2}$ \\
StD & 0,008 & 0,002 \\
C.V. $(\%)$ & 3,0 & 1,0 \\
$\lambda_{23, \text { dry,mat }(\mathbf{W} /(\mathbf{m} . \mathbf{K})) \mathbf{E N} \mathbf{1 7 4 5}}$ & 0,341 & 0,256 \\
\hline
\end{tabular}

Primerubber R20 presented higher water vapour permeability coefficient and water absorption by capillary action, higher density and higher thermal conductivity. Considering these results, rubber granulates might increase the amount of smaller pores, which lead to higher water vapour permeability and water absorption by capillary action. As expected, the increase of rubber in the composition of the mortar decreased its density, as rubber is lighter than natural sand. Also, considering the thermal behaviour of rubber, it was confirmed that the increase of the percentage of rubber decreases thermal conductivity.

Concerning the EN 998-1 specification standard, both Primerubber R20 and Primerubber R35 may be classified as $\mathrm{W}_{\mathrm{C}} 2$, as their capillary coefficient is equal to or less than $0,2 \mathrm{~kg} /\left(\mathrm{m}^{2} \cdot \mathrm{min}^{0.5}\right)$. Neither of the mortars can be classified as thermal insulating mortar. However, Primerubber R35 obtained a value close to a T2 classification $(\leq$ $0,2 \mathrm{~W} /(\mathrm{m} \cdot \mathrm{K}))$.

\subsection{Mortars classification}

Considering the parameters evaluated with the experimental campaign, it is possible to frame the studied mortars in the context of the specification standard for mortars for rendering and plastering, EN 998-1.

By analysing the requirements presented in Table 2 of the referred standard set for hardened mortars, it is confirmed that both mortars meet all the requirements for classification as GP, general purpose mortars, CR, coloured rendering mortars, and also LW, lightweight mortars, as their density is inferior to $1300 \mathrm{~kg} / \mathrm{m}^{3}$.

To be declared as thermal insulating mortars, T2, products must have a thermal conductivity equal to or less than $0,2 \mathrm{~W} /(\mathrm{m} . \mathrm{K})$. Primerubber R35 is very close to this limit, and, with a water vapour permeability coefficient under 15 , also complies with the requirement for water vapour permeability.

For the other types of mortars, the characterization performed was not sufficient in order to define the mortars as $\mathrm{OC}$, one-coat rendering mortar, or as $\mathrm{R}$, renovation mortars.

\section{Conclusions}

In the framework of the project "EFTM - Ecological and Functional Technical Mortars", which aimed for the development of ecological mortars with improved characteristics and ability for application onto several substrates and under different conditions, mortars incorporating recycled rubber granulates were produced and characterized. Two different compositions were developed and characterized in laboratory conditions, in the fresh and hardened state, from the mechanical and physical point of view. The obtained results enabled, not only the evaluation of the overall behaviour of the mortars, but also their framing within the requirements set by the specification standard for $\mathrm{CE}$ marking for mortars for rendering and plastering. 
It was observed that the global performance of rubber mortars is very satisfying. However, Primerubber R20 presented better mechanical behaviour and Primerubber R35 better physical behaviour. The adhesive strength of Primerubber R20 stands out, as this mortar presents high compatibility with different substrates. This aspect reinforces the multi-functionality, sustainability and versatility intended for these mortars.

However, given the results obtained, it was considered that these compositions need to be improved, so as to establish a compromise between the improved mechanical behaviour of Primerubber R20 and the improved physical behaviour of Primerubber R35. Also, an extended characterization is being performed in order to understand other physical properties, such as acoustic behaviour and durability of the mortars when exposed to accelerated ageing conditions and "in situ" conditions.

\section{Acknowledgements}

This work was framed within the CENTRO-01-0247-FEDER-017657 (EFTM) Project funded by Portugal 2020 through the COMPETE 2020.

\section{References}

[1] G. Matias, P. Faria, I. Torres, Lime mortars with heat treated clays and ceramic waste: A review, Construction and Building Materials 73 (2014) 125-136.

[2] G. Matias, P. Faria, I. Torres, Lime mortars with ceramic wastes: Characterization of components and their influence on the mechanical behavior, Construction and Building Materials 73 (2014) 523-534.

[3] J. António, A. Tadeu, A. Moreira, Impact sound transmission provided by concrete layers incorporating cork granules, Noise Control Engineering Journal 61-5 (2013) $458-468$.

[4] A. Tadeu, A. Moreira, J. António, N. Simões, I. Simões, Thermal delay provided by floors containing layers that incorporate expanded cork granule waste, Energy \& Buildings 68 (2014) 611-619.

[5] A. Moreira, J. António, A. Tadeu, Lightweight screed containing cork granules: Mechanical and hygrothermal characterization, Cement \& Concrete Composites 49 (2014) 1-8.

[6] D. Lucas, C. Benatti, Utilização de resíduos industriais para a produção de artefactos cimentícios e argilosos empregados na construção civil. Agronegócios e Meio Ambiente 1-3 (2008) 405-418.

[7] L. Škerget, A. Tadeu, BEM numerical simulation of coupled heat and moisture flow through a porous solid, Engineering Analysis with Boundary Elements 40 (2014) 154-161.

[8] I. Simões, N. Simões, A. Tadeu, Thermal Delay Simulation in Multilayer Systems using Analytical Solutions. Energy and Buildings 49 (2012) 631-639.

[9] A. Tadeu, P. Stanak, J. Sladek, V. Sladek, J. Prata, N. Simões, A coupled BEM-MLPG technique for the thermal analysis of nonhomogeneous media. CMES: Computer Modeling in Engineering \& Sciences 93-6 (2013) 489-516.

[10] A. Tadeu, P. Stanak, J. Sladek, V. Sladek, Coupled BEM-MLPG acoustic analysis for non-homogeneous media, Engineering Analysis with Boundary Elements 44 (2014) 161-169.

[11] S. Kristiawan, A. Hapsari, Delamination tendency of repair mortar incorporating crumb rubber, Sustainable Civil Engineering Structures and Construction Materials, SCESCM 2016, Procedia Engineering 171 (2017) 734-743.

[12] D. Jevtic, D. Zakic, A. Savic, Cement Based Composites Made With Recycled Rubber Aggregate, Hem. Ind. 66 (4) (2012) $609-617$.

[13] N. Medina et al. Mechanical and thermal properties of concrete incorporating rubber and fibres from tyre recycling, Construction and Building Materials 144 (2017) 563-573.

[14] A. Turatsinzea, S. Bonneta, J. Granjua, Mechanical characterisation of cement-based mortar incorporating rubber aggregates from recycled worn tyres, Building and Environment 40 (2005) 221-226.

[15] A. Angelin et al., The effects of porosity on mechanical behavior and water absorption of an environmentally friendly cement mortar with recycled rubber, Construction and Building Materials 151 (2017) 534-545.

[16] M. Merino, J. Astorqui, M. Cortina, Viability analysis and constructive applications of lightened mortar (rubber cement mortar). Construction and Building Materials 21 (2007) 1785-1791. 